punished, by the group's own decision, by sending the offender home. In practice, the rules were rarely broken, because to the boys they made sense.

From this it was an easy step to the acceptance of the Country Code itself, and the boys were often heard talking to their contemporaries about what should or should not be done in the country; and Mrs. Green suggested very reasonably that this is likely to have a far deeper effect than police warnings or slogans on the notice boards. With this went a changed attitude to farmers. Getting to know the farmers and understanding what farming meant changed the attitude of the boys into one of respect and co-operation: the farmer who had provided the site for the camp found his shippen cleaned out for him and a boy who admitted to knocking down dry-stone walls for years was found attempting to rebuild one.
Such changes alone would justify the continuance of such training camps from the point of view of the national parks and nature reserves alone, but the scheme also provided a definite programme for training the boys in climbing, in mountain rescue and in first-aid-at their own request. Here again the boys, from being a liability or a nuisance on the hills, became competent members of a mountain rescue team, and every challenge to endurance was met with enthusiasm. The experimental period described by Mrs. Green also showed the value of the scheme in developing the personalities of the boys. Much clearly depends on the quality of the staff, and there is also the matter of equipment; but the now training centre which opened in September 1959 offers a first-class mountaineering course for $5 s$. affiliation fee and $2 s$. $6 d$. at each school, and thirty boys are being taken.

\title{
APPLIED MATHEMATICS AND THEORETICAL PHYSICS AT CAMBRIDGE
}

\begin{abstract}
A DEVELOPMENT in the University of Cambridge which will be of interest generally is the formation, from October I, 1959, of a Department of Applied Mathematics and Theoretical Physics. The Department comes within the Faculty of Mathematics, and embraces the present teaching staff and research students on the applied side of the Faculty. Academic staff at Cambridge traditionally divide their time between centralized university lecturing and supervision of research students (as university lecturers, readers, etc.) on one hand, and informal teaching of undergraduates in their own college (as Fellows) on the other. This arrangement undoubtedly has advantages for undergraduates, but it has not been without some unfortunate consequences for research in a number of subjects. The various colleges provide their official Fellows with rooms, and the existence of this accommodation has retarded the development of centralized departments and buildings with adequate facilities for research. Teaching and research in the experimental sciences are impossible without a properly equipped laboratory, and these subjects were the first to be provided with central University buildings. Less obvious perhaps, but no less real, is the need for theoreticians to meet and work together in these days of rapid scientific developments and enlarging horizons. The formation of a Department of Applied Mathematics and Theoretical Physics at Cambridge is a recognition of this need, and is viewed as an administrative step towards the provision of central office accommodation and research facilities for the members of the Depart. ment. When that is achieved, an anomaly peculiar to the University of Cambridge will have been removed.
\end{abstract}

There are two novel features of the new Department. The first is that, as implied by the name, the Department includes both 'classical' and 'modern' aspects of theoretical physics and engineering science, in contrast to the usual plan in which applied mathematics and theoretical physics fall in separate university departments. This unity was suggested by the existing practice of teaching both applied mathematies and theoretical physics in the Mathematical Tripos; and it was in any event felt to be appropriate. The customary division between applied mathematics and theoretical physics is scientifically rather arbitrary (being prompted, perhaps, by the fact that in most universities applied mathematics is linked with pure mathematics and theoretical physics with physics) and is often unfortunate in its effects. Recent work on plasma physics and magneto-gasdynamics has shown how much the two subjects have in common and how artificial is the division between them; and the older fields of theoretical astronomy and astrophysics have long illustrated the same point. The staff at Cambridge who will comprise the new Department are eighteen in number, and are engaged on work in elementary particle and field theory, nuclear physics, astrophysics, plasma dynamics, fluid mechanics and geophysics.

The second novel feature is the provision that the head of the Department shall be appointed for five years at a time from among the more senior people in the Department. This represents a deliberate departure from the practice in British universities of having a head with life tenure, usually the sole professor, or, where there is more than one professor, the one of greatest scientific distinction, and is more like the arrangement in many American universities. The disadvantages and risks of having a permanent head are well known; the health and fate of the department are tied to the administrative ability and capacity for leadership of one person for many years, the growth of a hierarchial structure may be encouraged, the talents of a rising leader may not be given full scope, and so on. There are also advantages, which may be more important in some circumstances; but there was a strong feeling at Cambridge that a more flexible scheme was desirable for the new Department. A period of five years was chosen as being long enough to allow the head of the Department to formulate and carry through any schemes which may be close to his heart, and short enough to be regarded as only a temporary interruption of personal research. The regulations allow re-appointment of a person for further periods of five years. This experiment in administration of a university department will be interesting and may have its lessons for other departments.

The first head of the Department is Dr. G. K. Batchelor, reader in fluid mechanics. He is known 


\section{No. 4687 August 29, $1959 \quad$ N A T U R E}

for his work on the theory of turbulence and other branches of fluid mechanics, for which he was elected a Fellow of the Royal Society in 1957. Dr. Batchelor was born in Melbourne in 1920 and received his first degree from the University of Melbourne in 1940.
Later he went to Cambridge, where he was elected a Fellow of Trinity College in 1947 and awarded an Adams Prize in 1951. He is editor of the Cambridge Monographs on Mechanics and Applied Mathematics and of the Journal of Fluid Mechanics.

\section{ENZYMES}

$\mathrm{W}^{\mathrm{A}}$ AGENINGEN, situated on the Rhine in eastern Holland, contains 22,000 inhabitants, and about seventy institutes for seientific research. About one-half of these institutes form part of the State Agricultural University of Wageningen, while the other half are government or private institutes.

In these pleasant surroundings, a highly successful conference on enzymes was held by the University of Wageningen during April 6-9. The organizing committee was under the chairmanship of Prof. H. J. C. Tenderloo, with Dr. H. Veldkamp as secretary.

An introductory lecture was given by E. C. Slater (Amsterdam), who emphasized the central place of enzymology in biochemistry. In his view, it is enzymology which gives biochemistry its own methodology, and its own manner of thinking. (Later in the conference, H. Booij (Leyden), speaking as an 'angry young man', provided the necessary corrective against any over-enthusiastic adoption of this proposition by pointing out that other fields of biochemistry existed.) Although there are many different enzymes, the number of different reaction types catalysed by enzymes is quite small. Life, as we know it, involves comparatively fow chemical tricks, which are used over and over again, and the aim of biochemistry is to systematize our knowledge of these tricks. A significant step forward in the systematization of enzymology was the appearance in 1958 of the book "Enzymes", by M. Dixon and E. C. Webb. Studies of the mechanism of enzyme action by kinetic and isotopic methods, and by direct chemical studies in which the enzyme is used as a reactant, have confirmed the suggestion made by Michaelis and Menten in 1913 that the enzyme reacts with at least one of the substrates to give an intermediate enzyme-substrate compound. However, in many cases the intermediate enzyme-substrate compound contains only a part, sometimes a small part, of the substrate. This lecture also dealt with the uses which have been made of isolated enzymes as tools in other investigations, in particular in analytical procedures and in the determ. inations of the structures of compounds isolated from natural materials, such as coenzyme $\mathbf{A}$.

C. de Duve (Louvain) reviewed the recent know. ledge of the localization of enzymes within the cell, which has been gained by fractionation of cell homogenates, particularly by differential centrifugation. He pointed out that although the cytologist would regard the preparation of a tissue homogenate as a brutal disruption of the cell, this homogenate is able to carry out very many reactions, and it is possible to localize different reactions in different cell organellæe which can be isolated from the homogenate. He dealt at length with the theoretical basis of the various methods of separation which have been used, and discussed their advantages and disadvantages. The use of 'marker' enzymes for the main fractions of the rat-liver cell nucleus, mitochondria, microsomes and 'soluble' fraction has led de Duve to the discovery that many hydrolytic enzymes are present in granules a little smaller than mitochondria which he has named lysosomes. More recent work using the technique of density equilibrium in heavy water has suggested that at least two enzymes (uricase and catalase) are present in yet another type of granule. The enzymes within the lysosomes are inactive towards their substrates unless the granules are destroyed mechanically or by suspension in hypotonic solution. The lysosomes also discharge their enzymes into the cell when the latter becomes anaerobic, thus promoting autolysis of the cell.

P. Desnuelle (Marseilles) spoke about the chemical structure of proteins and mechanism of action of proteolytic enzymes. He pointed out that although the chemical structures of insulin and of the polypeptides melanocyte-stimulating hormone and adrenocorticotrophic hormone are now established, the reason for the activity of the whole molecule is not yet known. He discussed what is known about the primary, the secondary and the tertiary structures of proteins, emphasizing that although other structures are theoretically possible, the open-chain is the only type which has been clearly demonstrated. Desnuelle described recent work on the activation of the precursors (the -ogens) of the pancreatic proteolytic enzymes, which has shown the importance of limited proteolysis in this process. Actually, the activation of chymotrypsin and trypsinogen is brought about by the splitting of a single bond. But this splitting is likely to be the first and necessary step for deep changes in the tertiary structure of the precursor, bringing two or three residues at the right position in space for building an 'active centre'.

E. C. Webb (Cambridge) surveyed the properties of the various coenzymes, prosthetic groups and activators of enzymes. He pointed out that metals sometimes act as carriers, sometimes promote the combination of the enzyme with the substrate. The effects of anion activators were discussed in relation to his own recent studies of the activation of arylsulphatase by chloride.

A discussion between Dr. Webb and Prof. Slater on whether a valid distinction could be drawn between a coenzyme and a prosthetic group led to the agreed definition that a compound acts as a coenzyme if during the course of its catalysis of the reaction it reacts first with one enzyme and then with another, and as a prosthetic group if it remains bound to the one enzyme during the course of the reaction. The same substance can in different reactions act as a substrate, a coenzyme or a prosthetic group.

Sir Rudolph Peters (Cambridge) discussed enzyme inhibitors, illustrating the different types by reference to carbon-fluorine compounds (for example, fluorocitrate), arsenicals and organo-phosphorus compounds. The recent studies at Babraham on the mechanism of the inhibition of aconitase 